\title{
Factors influencing long-term prognosis in male patients surviving a first coronary attack
}

\author{
Risteard Mulcahy, Noel Hickey, Ian Graham, and Gilbert McKenzie \\ From the Coronary Heart Disease Research Unit, St. Vincent's Hospital, Dublin; and the Departments \\ of Medicine and of Social and Preventive Medicine, University College, Dublin; and the \\ Department of Social and Preventive Medicine, Queen's University, Belfast
}

Three hundred and sixty-four men who survived a first episode of acute coronary insufficiency or myocardial infarction for 28 days were admitted to a coronary heart disease secondary prevention programme between $I$ Fanuary I96I and 31 December I97I. Of these, 252 have been followed far at least 4 years. The 4-year mortality was 13.5 per cent (34 patients). The average annual mortality was 3.4 per cent but an excess of deaths occurred during the first year of follow-up.

Of II characteristics measured during the acute attack, only severity of the attack was significantly associated with poor 4-year survival.

Cigarette consumption after infarction was significantly less among those surviving the 4-year period when compared with decedents. Follow-up systolic and diastolic blood pressure levels were significantly lower among decedents. No significant differences were noted in serum cholesterol levels and in mean weight. The presence of post-infarction angina did not affect the prognosis.

Epidemiological research has yet to provide a definite risk factor profile of the coronary-prone individual. Many factors have been incriminated to varying degrees, including hypertension, hyperlipidaemia, cigarette smoking, obesity, family history, water hardness, and sociopsychological factors (Cady, 1967; Dudley, Beldin, and Johnson, 1969; Rosenman et al., 1970; Chapman et al., 1971; Heady, 1973). Few controlled single or multiple factor population prospective trials have been undertaken to quantify rigorously the hypothesis that reduction in coronary heart disease incidence can be achieved through risk factor intervention.

Although the pathogenetic mechanisms of atheroma have not been identified, secondary prevention programmes may provide the means by which the prognosis of individuals with newly diagnosed coronary heart disease can be improved. Successful rehabilitation and improved survival in patients with coronary heart disease are the twin objectives of secondary prevention. In addition, a framework is established within which the clinician may test the efficacy of various treatment regimens on survival.

Received 4 July 1974 .
The object of this report is to record the survival experience of our male patients who have survived a first coronary attack and to identify initial and longterm determinants of prognosis among them. The methods of our follow-up study have been described previously (Mulcahy and Hickey, 1972).

\section{Subjects and methods}

Three-hundred and sixty-four consecutive male patients under 60 years who survived a first attack of acute coronary insufficiency or myocardial infarction for at least 28 days were admitted to a rehabilitation and secondary prevention programme between I January I96I and 3I December 1971. Of these, 259 entered the study at or before 3I December 1968 and were, therefore, theoretically eligible for inclusion in this 4-year follow-up study. The 259 initial and fourth year follow-up records were extracted from the secondary prevention follow-up file. At the time of writing the follow-up status of 3 cases was indeterminable. A further 4 cases were excluded from the analysis as 'outliers'1 (Cox and Snell, 1968), leaving in total, 252 patients - the index

${ }^{1}$ In these 4 cases a number of the biochemical measurements departed so far from the mean that their inclusion in the analysis would have seriously biased the results. 
cases - satisfying the medical and statistical criteria for inclusion in the analysis.

Although nominally the follow-up period is 4 years, operationally some variation was experienced. The average follow-up period for the 218 survivors was 48.89 ( \pm 5 months) and 80 per cent were followed up between 42 and 54 months. The remaining 20 per cent were all examined between 36 and 60 months. The survivorship distribution of the 34 deaths is discussed separately in the results, section A. The term 4-year follow-up refers to an average follow-up period of 48.89 months.

Last follow-up was taken as the last outpatient visit. In the decedent group, last follow-up examination took place some time before death. In no case was it felt that the terminal illness influenced the last follow-up findings appreciably.

The 252 index cases were classified into 3 severity groups as follows:

a) Acute coronary insufficiency, $66(26.2 \%)$

b) Myocardial infarction, 140 (55.6\%)

c) Myocardial infarction (complicated), 46 (18.2\%)

Patients with acute coronary insufficiency had typical cardiac pain and serial electrocardiographic abnormalities without enzyme changes or other indications of heart muscle necrosis (Mulcahy and Hickey, 1966).

Patients with myocardial infarction had typical cardiac pain with characteristic electrocardiographic abnormalities of infarction and/or enzyme changes (Mulcahy and Hickey, I966). They were designated complicated if, during the acute stage, one or more of the following conditions presented: I) supraventricular tachyarrhythmias; 2) ventricular tachycardia; 3) second-degree or complete heart block; 4) prolonged hypotension; 5) cardiogenic shock; 6) cardiac failure (frank left or right ventricular failure or pulmonary congestion in the $x$-ray); 7) pericarditis, with or without post-infarction syndrome; 8) thromboembolism, including systemic as well as pulmonary embolism; 9) Bundle-branch block, transient or persistent, with QRS complexes of $0.12 s$ or more.

Additional complications are now included in this continuing study but they were not recorded before the development of coronary care facilities.

Our report concentrates on the measurements, height, weight, systolic and diastolic blood pressure, serum cholesterol, number of cigarettes smoked per day, lifetime smoking or cigarette index (Mulcahy, Hickey, and McDonald, 1966), anginal status, age, family history, and severity of initial myocardial infarction. The same information was available at fourth year follow-up or, in the case of decedents, at last follow-up.

\section{Results}

\section{A) Length of survival of decedents}

Thirty-four index cases ( $13.5 \%$ ) had died and 218 $(86.5 \%)$ were alive at the end of the 4-year followup period. Table I shows the observed survival time distribution for the decedent group. Eight patients $(23.5 \%)$ died within 6 months of initial infarction, and $14(41 \%)$ were dead within I year. The hypothesis of equal risk of death in each year after initial attack was easily rejected $\left(\chi^{2}=10.87\right.$, d.f. $=3, P<0.05)$. The mean survival time for the 34 decedent index cases was $20.2( \pm 2.42)$ months.

The doubly truncated exponential distribution was fitted to the distribution of decedents (Table $\mathrm{r}$ ). Details of this one parameter distribution are given in the appendix. An adequate fit to the observed survival times of the decedents was obtained $\left(\chi^{2}=7.43\right.$, d.f. $\left.=3, P>0.05\right)$, though an aberrant sampling fluctuation in the ' 25 to 31 months category' contributed substantially to the excess mortality observed in the tail. Nevertheless, it is concluded that this statistical model provides a reasonable basis upon which to make inferences about the survival distribution of decedents. In simple terms, this statistical technique confirms that the mortality rate after a first coronary attack is not constant over the follow-up period, and that mortality experience may tend to improve with length of survival.

\section{B) Comparison of initial characteristics in survivors and decedents}

Table 2 shows, for both groups, the mean values obtained for eight continuously distributed measurements made at initial examination. No statistically significant differences were observed, and it is concluded that taken individually these variables are not important determinants of 4 years' survival.

The distribution of anginal status was examined. Of those with angina before their illness, 19 per cent died, while II.6 per cent of those without angina died. The 7.4 per cent difference was not statistically significant at the 5 per cent level $\left(\chi^{2}=\mathbf{2 . 2 2}\right.$, d.f. $=$ I, $P>0.05$ ). Similarly, no significant difference was observed in the death rates of each of the four categories (negative $12.9 \%$, doubtful $11.6 \%$, positive $21.1 \%$, strongly positive $14.8 \%$ ) of family history $\left(\chi^{2}=2.12\right.$, d.f. $\left.=4, \mathrm{P}>0.05\right)$.

Table 3 shows the distribution of severity of the initial attack in both survivors and decedents. Patients experiencing a complicated myocardial infarction had a worse prognosis, I4 (30.4\%) being dead at fourth year follow-up compared with I6 ( $11.4 \%)$ in the uncomplicated myocardial infarction group and $4(6.1 \%)$ in the acute coronary insufficiency group $\left(\chi^{2}=14.95\right.$, d.f. $\left.=2, \mathrm{P}<0.00 \mathrm{r}\right)$.

Because of the inadequacies of single factor analysis a linear discriminant function analysis (Fisher, 1938) utilizing the above 8 continuously distributed measurements, as well as anginal status (scored $\mathrm{I}$ if present, and $\mathrm{o}$ if absent), family history, and severity of initial attack, was undertaken. A 
TABLE I Distribution of survival-times in 34 patients who died within 4 years of entry to study

\begin{tabular}{llrlr}
\hline $\begin{array}{l}\text { Time } \\
\text { from entry } \\
\text { to study } \\
\text { (mth) }\end{array}$ & $\begin{array}{l}\text { Observed } \\
\text { frequency }\end{array}$ & $\%$ & $\begin{array}{l}\text { Expected } \\
\text { frequency }\end{array}$ & $\%$ \\
\hline I- & & & & \\
$7-$ & 8 & 23.5 & 8.32 & 24.5 \\
I3- & 6 & 17.6 & 7.51 & 22.1 \\
19- & 2 & 5.9 & 5.50 & 16.2 \\
$25-$ & 3 & 8.8 & 4.02 & 11.8 \\
$31-$ & 7 & 20.6 & 2.94 & 8.7 \\
$37-$ & 3 & 8.8 & 2.15 & 6.3 \\
$43-$ & 3 & 8.8 & 1.57 & 4.6 \\
$49-$ & 1 & 2.9 & 1.15 & 3.4 \\
Total & 1 & 2.9 & 0.85 & 2.5 \\
& 34 & $(100)$ & 34 & $(100)$ \\
\hline
\end{tabular}

$\lambda=0.052 \mathrm{I}( \pm 0.0085)-$ see appendix.

$\star$ Derived from the doubly truncated exponential law (see Appendix).

comparison of the average discriminant scores obtained failed to reach statistical significance $\left(\chi^{2}=24.56\right.$, d.f. $\left.=15, \mathrm{P}>0.05\right)$. It is considered that, of the intial factors, only severity of the initial attack shows a statistically significant relation with survivorship status at 4 years.

\section{C) Comparison of follow-up characteristics in survivors and decedents}

Table 4 indicates significant mean differences between survivors and decedents with respect to systolic blood pressure, diastolic blood pressure, and cigarette smoking. The mean values of both blood pressure measurements are raised in survivors and decedents at last follow-up but the rise was significantly greater in the survivors.

On average, survivors were smoking 8 cigarettes a day less than decedents $(P<0.00 \mathrm{I})$. This difference between survivorship groups is independent of the initial cigarette consumption and all other measures recorded at both initial examination and at fourth year examination. The partial ' $t$ ' statistic produced by the stepwise discriminant function algorithm was $-4.16, \mathrm{P}<0.001$.

The serum cholesterol levels of survivors were lower than those of the decedents but the difference was not significant. No significant difference was evident in mean weight.

Survivorship showed no relation with postinfarction angina at 4-year follow-up (or at last follow-up in decedents). Of the 79 cases in whom angina was present, $12(15.2 \%)$ died, while the corresponding figure in those without angina was 22 $(12.7 \%)\left(\chi^{2}=0.28\right.$, d.f. $\left.=I, P>0.05\right)$.

D) Comparison of mean changes occurring in selected characteristics between initial and last examination in survivors and decedents

The mean changes in systolic and diastolic blood pressure, serum cholesterol, cigarette consumption, and weight over the follow-up period are shown for both groups in Table 5. Non-significant changes in systolic blood pressure, diastolic blood pressure, serum cholesterol and weight are observed in the 34 decedents, while a statistically significant decrease of 9.2 cigarettes a day occurred. In the survivors group statistically significant reductions were recorded in serum cholesterol (on average $10.4 \mathrm{mg}$ / $100 \mathrm{ml}$ ) and in cigarettes a day (on average 16.5

TABLE 2 Intersurvivorship group comparisons: mean values of continuously distributed measurements made at initial examination

\begin{tabular}{|c|c|c|c|c|c|c|c|}
\hline Variable & $\begin{array}{l}\text { Group means } \\
\text { Decedents } \\
(n=34)\end{array}$ & $( \pm S E)$ & $\begin{array}{l}\text { Survivors } \\
(n=218)\end{array}$ & $( \pm S E)$ & Differences * & $( \pm S E)$ & Probability \\
\hline $\begin{array}{l}\text { Height (cm) } \\
\text { Weight (kg) } \\
\text { Systolic BP (mmHg) } \\
\quad(k P a) \\
\text { Diastolic BP (mmHg) } \\
\quad(k P a) \\
\text { Cholesterol } \\
\quad(\mathrm{mg} / 100 \mathrm{ml}) \\
\text { Cigarettes/day } \\
\text { Cigarette indext } \\
\text { Age last birthday }\end{array}$ & $\begin{array}{c}173.8 \\
73.9 \\
128.03 \\
17.0 \\
81.26 \\
10.8 \\
\\
262.28 \\
22.41 \\
645.41 \\
51.35\end{array}$ & $\begin{array}{l}( \pm 1.24) \\
( \pm 1.9) \\
( \pm 3.21) \\
( \pm 0.4) \\
( \pm 1.95) \\
( \pm 0.2) \\
( \pm 8.43) \\
( \pm 2.53) \\
( \pm 50.77) \\
( \pm 1.00)\end{array}$ & $\begin{array}{l}173.2 \\
74.8 \\
126.43 \\
16.8 \\
79.69 \\
10.6 \\
\\
265.80 \\
21.63 \\
628.34 \\
50.50\end{array}$ & $\begin{array}{l}( \pm 0.43) \\
( \pm 0.8) \\
( \pm 1.21) \\
( \pm 0.16) \\
( \pm 0.70) \\
( \pm 0.1) \\
( \pm 3.12) \\
( \pm 1.04) \\
( \pm 22.71) \\
( \pm 0.44)\end{array}$ & $\begin{array}{l}+0.6 \\
-0.9 \\
+1.60 \\
+0.2 \\
+1.57 \\
+0.2 \\
+3.52 \\
+0.78 \\
+17.07 \\
+0.85\end{array}$ & $\begin{array}{l}( \pm 1.2) \\
( \pm 2.1) \\
( \pm 3.33) \\
( \pm 0.4) \\
( \pm 1.94) \\
( \pm 0.2) \\
( \pm 8.60) \\
( \pm 2.82) \\
( \pm 61.13) \\
( \pm 1.19)\end{array}$ & $\begin{array}{l}0.72 \\
0.69 \\
0.64 \\
0.42\end{array}$ \\
\hline
\end{tabular}

$\star$ Decedents - survivors.

† Measurement of lifetime smoking (Mulcahy et al., 1966).

Blood pressures in pascal units are given in italics. 
cigarettes a day). Statistically significant increases were recorded in both blood pressure measurements.

From the last two columns of Table 5 it is apparent that the average increase in blood pressure measurements in the survivors was significantly greater than the corresponding increase in the decedents. No statistically significant difference was found on average in the amount by which both survivors and

TABLE 3 Distribution of severity of initial attack in both survivorship groups

\begin{tabular}{|c|c|c|c|}
\hline \multirow[b]{2}{*}{ Severity } & \multicolumn{2}{|c|}{ Survivorship group } & \multirow[b]{2}{*}{ Total } \\
\hline & Dead & Alive & \\
\hline $\begin{array}{l}\text { Acute coronary } \\
\text { insufficiency }\end{array}$ & $4(6.1)$ & 62 (93.9) & 66 (100) \\
\hline $\begin{array}{l}\text { Myocardial infarction } \\
\text { (uncomplicated) }\end{array}$ & I6 (II.4) & $124(88.6)$ & $140(100)$ \\
\hline $\begin{array}{l}\text { Myocardial infarction } \\
\text { (complicated) } \\
\text { Total }\end{array}$ & $14(30.4)$ & $\begin{array}{r}32(69.6) \\
218(86.5)\end{array}$ & $\begin{array}{r}46(100) \\
252(100)\end{array}$ \\
\hline Total & $34(13.5)$ & $218(86.5)$ & $252(100)$ \\
\hline
\end{tabular}

$\chi^{2}=14.95$, d.f. $=2, P<0.05$. non-survivors reduced their serum cholesterol and weight. However, the survivors did significantly reduce their cigarette consumption by $16.44 \mathrm{cig}$ arettes a day compared with a reduction of 9.18 cigarettes a day in the non-survivors.

Anginal status was next examined. Of the 79 patients with angina at last follow-up, 15.2 per cent ( 12 cases) were dead. The rates for comparison are 19.0 per cent (initial examination) and 15.2 per cent (follow-up examination). A non-significant result is obtained and no important increase in the proportion of deaths was observed in those patients experiencing angina at follow-up.

The variables in Table 5 and anginal status were used in another discrimination function analysis. Bartlett's test revealed a statistically significant difference $\left(\chi^{2}=25.76\right.$, d.f. $\left.=6, P<0.01\right)$. However, when the mean discriminant scores were examined the degree of group separation was poor: an application of Bayes' theorem resulted in some $215(98.6 \%)$ of the survivors and only $2(5.9 \%)$ of the decedents being correctly classified.

TABLE 4 Intersurvivorship group comparisons: mean values of continuously distributed measurements made at follow-up examination at 4 years (survivors) and last available follow-up (decedents)

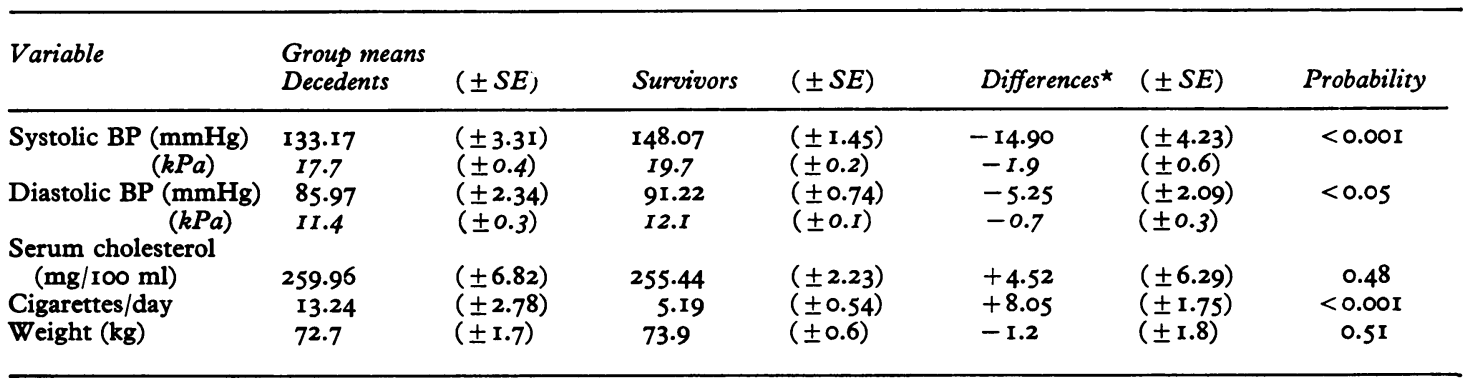

* Decedents - survivors.

Blood pressures in pascal units are given in italics.

TABLE 5 Intersurvivorship group comparisons: mean values of changes in five continuously distributed measurements between those observed on entry and last available examination

\begin{tabular}{|c|c|c|c|c|c|c|c|}
\hline Variables & $\begin{array}{l}\text { Group means } \\
\text { Decedents }\end{array}$ & $( \pm S E)$ & Survivors & $( \pm S E)$ & Differences * & $( \pm S E)$ & Probability \\
\hline Systolic BP $\underset{(k P a)}{\left(\mathrm{mmHg}^{2}\right)}$ & $\begin{array}{l}+5.14 \\
+0.68\end{array}$ & $\begin{array}{l}(3.25) \\
(0.43)\end{array}$ & $\begin{array}{l}+21.64 \\
+2.87\end{array}$ & $\begin{array}{l}(1.57) \\
(0.20)\end{array}$ & $\begin{array}{r}-16.50 \\
-2.19\end{array}$ & $\begin{array}{l}(4.20) \\
(0.56)\end{array}$ & $<0.001$ \\
\hline $\begin{array}{l}\text { Diastolic } \mathrm{BP}(\mathrm{mmHg}) \\
\begin{array}{c}(\mathrm{mPa}) \\
\text { Serum cholesterol }\end{array}\end{array}$ & $\begin{array}{l}+4.70 \\
+0.62\end{array}$ & $\begin{array}{l}(2.69) \\
(0.36)\end{array}$ & $\begin{array}{l}+11.54 \\
+1.53\end{array}$ & $\begin{array}{l}(0.81) \\
(0.10)\end{array}$ & $\begin{array}{l}-16.24 \\
-2.15\end{array}$ & $\begin{array}{l}(2.32) \\
(0.3 I)\end{array}$ & $<0.01$ \\
\hline $\begin{array}{c}(\mathrm{mg} / \mathrm{IO} \mathrm{ml}) \\
\text { Cigarettes/day }\end{array}$ & $\begin{array}{l}-2.32 \\
-9.18\end{array}$ & $\begin{array}{l}(6.34) \\
(\mathbf{2 . 2 8})\end{array}$ & $\begin{array}{l}-10.36 \\
-16.44\end{array}$ & $\begin{array}{l}(3.15) \\
(1.00)\end{array}$ & $\begin{array}{l}+8.04 \\
+7.26\end{array}$ & $\begin{array}{l}(8.39) \\
(2.70)\end{array}$ & $\begin{array}{r}0.34 \\
<0.01\end{array}$ \\
\hline Weight (kg) & -1.23 & $(0.73)$ & -0.86 & $(0.49)$ & -0.37 & (1.29) & 0.76 \\
\hline
\end{tabular}

^ Decedents - survivors.

Blood pressures in pascal units are given in italics. 


\section{Discussion}

Pell and D'Alonzo (1964) reviewed ro studies reporting long-term survival after acute coronary disease. All these studies differed in such important aspects as diagnostic criteria, sex and age distribution of patients, and follow-up methodology. The 5-year survivorship varied from 49 to $83 \mathrm{per}$ cent.

In a more recent study (Geismar et al., 1973) a 5year survivorship of 56 per cent among 642 patients with coronary heart disease who survived to leave hospital was reported. In a study of 598 men who survived an infarction for 4 weeks, Zukel et al. (1969) reported a 5-year survivorship of 80 per cent while the HIP study (Weinblatt et al., 1968) showed an 81 per cent survivorship over $4 \frac{1}{2}$ years among similar patients.

Our study reports an 86.5 per cent survivorship over 4 years in men under 60 years with first myocardial infarction or acute coronary insufficiency. Our results are similar to those of Zukel et al. (1969) and the HIP group, which, perhaps more than any other studies, resemble our own in relation to age distribution, diagnostic criteria, and time of start of follow-up.

About 40 per cent of our decedents died during the first year of follow-up. A higher death rate in the first year has been reported by Weinblatt et al. (1968) and this fact may have important implications from the secondary prevention point of view. It is at least worth speculating that, if secondary prevention measures are effective, they may not affect mortality for some time after they are instituted. In such an event one might find that the beneficial influences of these measures might not be detected until some time after the heart attack.

To achieve valid results, a controlled randomized study of the effects of secondary prevention measures on survival in patients with coronary heart disease would be required, but for practical and indeed ethical reasons such a programme is virtually impossible to organize. However, by examining survival curves among particular groups within the entire cohort it should be possible to detect the effect of various initial and follow-up attributes on long-term survival. It might be feasible to establish prognostic criteria for patients according to the nature of the coronary attack and to their attributes at the time of the attack. Similar criteria might also be established based on risk factor changes in response to a secondary prevention programme occurring during the follow-up period.

We have shown that, of II initial factors studied, only the severity of the initial attack influenced long-term prognosis. Unlike the HIP study (Frank et al., 1968) we did not find that the initial systolic or diastolic blood pressure status influenced longterm survival.

Increasing age was associated with increasing mortality over 4 years in our group, but the association was not significant. In a study of patients under 40 years with coronary heart disease a worse longterm prognosis was noted in the younger survivors (Gertler et al., 1964), while in the HIP study (Frank et al., 1968) the mortality was higher in older patients. In the seven countries study (Keys, 1970) age had no obvious effect on survivorship. It may be that the older the age group the more likely one is to find that age is positively associated with a less favourable long-term prognosis.

The presence of angina before the initial attack had no significant influence on prognosis in our experience though the HIP study (Weinblatt et al., 1968) showed angina to have an adverse effect on longterm mortality.

As in the HIP study (Weinblatt et al., I968) we found no relation between current and lifetime smoking noted at initial attack and 4-year survival. Initial cholesterol figures bore no relation to longterm prognosis, a finding that supports those of other workers (Keys, 1970; Shanoff, Little, and Csima, 1970).

The presence of complications such as left ventricular failure and prolonged hypotension remains the only detectable initial determinant of prognosis in these patients. This finding has been reported in the past and, in general, investigators have reported poor long-term survival experience among those with cardiac failure, dyskinesis, life-threatening arrhythmias, and cardiomegaly during the acute stage (Honey and Truelove, 1957; Pell and D'Alonzo, 1964; Beard et al., 1967; Weinblatt et al., 1968; Norris et al., 1973). In addition, some workers (Pell and D'Alonzo, I964; Sievers, I964) find that the adverse effect of complications during the acute stage on long-term survival is apparent only for the initial I to 2 years of survival, and that patients with initially complicated myocardial infarcts who survive this early period appear to have a prognosis no worse than that of those who survive an uncomplicated myocardial infarct.

We have recorded the nature of the different complications during the acute stage in all our patients. The number of patients who have died during follow-up is not large enough yet to identify the individual complications which may be the best determinants of poor prognosis, but preliminary examination of our data suggests that frank pulmonary oedema during the acute stage is a highly significant pointer to high subsequent mortality.

In the later stages of this study since the advent of coronary care facilities we have been able to 
record a greater variety of complications during the acute stage, but the influence of these recently recorded complications must await further followup.

Very little information is available about the effect of alteration of risk factors on survival in patients with myocardial infarct or acute coronary insufficiency. We have shown that our decedents and survivors had significantly reduced cigarette smoking, but the reduction in smoking experience was significantly greater in survivors compared to decedents. As far as we know this favourable experience among those who reduce their smoking considerably has not been previously reported.

There was a small but significant reduction in cholesterol levels in our patients but, while cholesterol reduction was greater among survivors, it was not significantly so compared to decedents.

Appropriate dietary or drug treatment will lower serum cholesterol in hypercholesterolaemic subjects. However, whether such a reduction will influence subsequent coronary heart disease mortality has yet to be decided. A study by Miettinen et al. (1972) suggests that cholesterol reduction is effective in reducing mortality in a primary prevention trial, and a few secondary prevention trials (Morrison, 1960; Leren, 1967; Bierenbaum et al., 1973) support this finding. However, the methods of these secondary prevention trials have been criticized. Among other factors, weight as a variable was not controlled and the treatment groups described showed a reduction in weight while the control group did not.

In 3 other secondary prevention trials (Ball et al., 1965; Rose, Thomson, and Williams, I965; Medical Research Council, 1968) the effect of obesity as a variable was reduced or eliminated in both control and treatment groups. None of these trials showed a significant difference in mortality in treated and untreated patients, despite a reduction in serum cholesterol in the treated group.

There is as yet no evidence that control of high blood pressure in survivors with coronary heart disease has any beneficial effect in preventing further coronary attack. Survivors and decedents showed similar mean systolic and diastolic blood pressure levels during the initial hospitalization. Both groups showed similar rises in blood pressure at first follow-up examination (Table 6). At last follow-up examination, however, while the blood pressure figures of the survivors were sustained, those of the decedents showed a significant fall towards the lower levels noted in hospital during the initial illness (Table 6).

The rise in blood pressure in both groups at first follow-up examination can be attributed to the known fact that inpatient blood pressure figures are significantly lower than casual outpatient figures. However, the subsequent fall in blood pressure among decedents cannot easily be explained. These patients may have been successfully treated for hypertension or they may have sustained further non-fatal myocardial infarcts to account for these findings. The significant fall in blood pressures during follow-up decedents at least merits further study and suggests the need for a careful evaluation of the indications for treatment of hypertension in patients with coronary heart disease.

Just as anginal status before the attack is a poor determinant of long-term prognosis, so is the anginal status of patients after the attack. While those with residual angina fared less well, the

TABLE 6 Intersurvivorship group comparisons of mean blood pressure (systolic and diastolic) levels at initial, first follow-up, and fourth year follow-up examination *

\begin{tabular}{|c|c|c|c|c|c|c|c|}
\hline \multirow{2}{*}{$\begin{array}{l}\text { Survivorship } \\
\text { group }\end{array}$} & \multicolumn{3}{|c|}{$\begin{array}{l}\text { Blood pressure }(\mathrm{mmHg})(\mathrm{kPa}) \\
(A) \\
\text { Initial examination }\end{array}$} & \multicolumn{2}{|c|}{$\begin{array}{l}\text { (B) } \\
\text { Ist follow-up examination }\end{array}$} & \multicolumn{2}{|c|}{$\begin{array}{l}(C) \\
\text { 4th year examination }\end{array}$} \\
\hline & $\left\{\begin{array}{l}\text { Systolic } \\
\text { Diastolic }\end{array}\right.$ & $\begin{array}{r}126.43 \\
I 6.8 I \\
79.69 \\
I 0.59\end{array}$ & $\begin{array}{l}( \pm I .2 I) \\
( \pm 0.16) \\
( \pm 0.70) \\
( \pm 0.09)\end{array}$ & $\begin{array}{r}146.89 \\
I 9.54 \\
91.53 \\
I 2.17\end{array}$ & $\begin{array}{l}( \pm 1.08) \\
( \pm 0.14) \\
( \pm 0.52) \\
( \pm 0.07)\end{array}$ & $\begin{array}{c}I 48.07 \\
I 9.69 \\
91.22 \\
I 2.13\end{array}$ & $\begin{array}{l}( \pm 1.45) \\
( \pm 0.19) \\
( \pm 0.74) \\
( \pm 0.09)\end{array}$ \\
\hline Dead & $\left\{\begin{array}{l}\text { Systolic } \\
\text { Diastolic }\end{array}\right.$ & $\begin{array}{r}128.03 \\
I 7.03 \\
81.26 \\
I 0.80\end{array}$ & $\begin{array}{l}( \pm 3.21) \\
( \pm 0.43) \\
( \pm 1.95) \\
( \pm 0.26)\end{array}$ & $\begin{array}{r}145.56 \\
I 9.36 \\
94.13 \\
I 2.51\end{array}$ & $\begin{array}{l}( \pm 2.27) \\
( \pm 0.30) \\
( \pm 1.59) \\
( \pm 0.21)\end{array}$ & $\begin{array}{r}I 33.17 \\
I 7.7 I \\
85.97 \\
I I .43\end{array}$ & $\begin{array}{l}( \pm 3.31) t \\
( \pm 0.44) \\
( \pm 2.34) \dagger \\
( \pm 0.3)\end{array}$ \\
\hline
\end{tabular}

\footnotetext{
$\star$ Standard errors in parentheses.

+ Last follow-up.

Blood pressures in pascal units $(\mathrm{kPa})$ are given in italics.
} 
mortality rate in those with and without angina was not significantly different. There is no information available from other sources about the influence of residual angina on prognosis.

We are grateful to Professor Peter Frogatt for his assistance.

This work is supported by The Medical Research Council of Ireland and The Irish Heart Foundation.

\section{References}

Ball, K. P., Hanington, E., McAllen, P. M., Pilkington, T. R. E., Richards, J. M., Sharland, D. E., Sowry, G. S. C., Wilkinson, P., Clarke, J. A. C., Murland, C. and Wood, J. (1965). Low-fat diet in myocardial infarction. Lancet, 2, 50I.

Beard, O. W., Hipp, H. R., Robins, M., and Verzolini, V. R. (1967). Initial myocardial infarction among veterans: tenyear survival. American Heart fournal, 73, 317.

Bierenbaum, M. L., Fleischman, A. I., Raichelson, R. I., Hayton, T., and Watson, P. B. (1973). Ten-year experience of modified-fat diets on younger men with coronary heart-disease. Lancet, I, 1404 .

Cady, L. D. (1967). Epidemiology of coronary heart disease. American fournal of Cardiology, 20, 692.

Chapman, J. M., Coulson, A. H., Clark, V. A., and Borun, E. R. (I97I). The differential effect of serum cholesterol, blood pressure and weight on the incidence of myocardial infarction and angina pectoris. Fournal of Chronic Diseases, 23, $63 \mathrm{I}$.

Cox, D. R., and Snell, E. J. (1968). A general definition of residuals (with discussion). fournal of the Royal Statistical Society, Series B, 30, 248.

Dudley, E. F., Beldin, R. A., and Johnson, B. C. (1969) Climate, water hardness and coronary heart disease. Fournal of Chronic Diseases, 22, 25.

Fisher, R. A. (1938). The statistical utilization of multiple measurements. Annals of Eugenics, 8, 376.

Frank, C. W., Weinblatt, E., Shapiro, S., and Sager, R. C. (I968). Prognosis of men with coronary heart disease as related to blood pressure. Circulation, 38, 432.

Geismar, P., Iversen, E., Mosbech, J., and Deyev, K. (1973). Longterm survival after myocardial infarction: a national follow-up study of 642 patients in Denmark. International fournal of Epidemiology, 2, 257.

Gertler, M. M., White, P. D., Simon, R., and Gottsch, L. G. (1964). Longterm follow-up study of young coronary patients. American fournal of the Medical Sciences, 247, 145.

Heady, J. A. (1973). A cooperative trial on the primary prevention of ischaemic heart disease using clofibrate: design, methods, and progress. Bulletin of the World Health Organization, 48, 243.

Honey, G. E., and Truelove, S. C. (1957). Prognostic factors in myocardial infarction. Lancet, $\mathbf{I}, 1209$.

Keys, A. (1970). (Editor.) Coronary Heart Disease in Seven Countries. American Heart Association, Monograph No 29. New York.

Leren, P. (1967). The effect of plasma cholesterol lowering diet in male survivors of myocardial infarction. A controlled clinical trial. Acta Medica Scandinavica, Suppl. 466.
Medical Research Council, Report of a Research Committee (1968). Controlled trial of soya-bean oil in myocardial infarction. Lancet, 2, 693.

Miettinen, M., Turpeinen, O., Karvonen, M. J., Elosuo, R., and Paavilaihen, E. (1972). Effect of cholesterol-lowering diet on mortality from coronary heart-disease and other causes. Lancet, 2,835 .

Morrison, L. M. (1960). Diet in coronary atherosclerosis. Fournal of the American Medical Association, 173, 884.

Mulcahy, R., and Hickey, N. (1966). Cigarette smoking habits of patients with coronary heart disease. British Heart fournal, 28, 404.

Mulcahy, R., and Hickey, N. (1972). Coronary Heart Disease Rehabilitation and Secondary Prevention Programme: A Research Study. St. Vincent's Hospital, Dublin.

Mulcahy, R., Hickey, N., and McDonald, M. (I966). A note on a quantitative method of recording cigarette smoking experience. Irish fournal of Medical Science, No. 487, 301.

Norris, R. M., Caughey, D. E., Deeming, L. W., Mercer, C. J., and Scott, P. J. (1973). Prognosis following acute myocardial infarction. New Zealand Medical fournal, 77, 12.

Pell, S., and D'Alonzo, C. A. (1964). Immediate mortality and five-year survival of employed men with a first myocardial infarction. New England fournal of Medicine, 270, 915.

Rose, G. A., Thomson, W. B., and Williams, R. T. (1965). Corn oil in treatment of ischaemic heart disease. British Medical fournal, I, I 531 .

Rosenman, R. H., Friedman, M., Straus, R., Jenkins, C. D., Zyzanski, S. J., and Wurm, M. (r970). Coronary heart disease in the Western collaborative group study. Fournal of Chronic Diseases, 23, 173.

Shanoff, H. M., Little, J. A., and Csima, A. (1970). Studies of male survivors of myocardial infarction. XII. Relation of serum lipids and lipoproteins to survival over a 10-year period. Canadian Medical Association fournal, 103, 927.

Sievers, J. (1964). Myocardial infarction. Clinical features and outcome in three thousand thirty-six cases. Acta Medica Scandinavica, 175, Suppl. 406.

Weinblatt, E., Shapiro, S., Frank, C. W., and Sager, R. V. (1968). Prognosis of men after first myocardial infarction: mortality and first recurrence in relation to selected parameters. American fournal of Public Health, 58, 1329.

Zukel, W. J., Cohen, B. M., Mattingly, T. W., and Hrubec, Z. (1969). Survival following first diagnosis of coronary heart disease. American Heart fournal, 78, 159.

Requests for reprints to Dr. Risteard Mulcahy, Coronary Heart Disease Research Unit, St. Vincent's Hospital, Elm Park, Dublin 4.

\section{Appendix}

The probability density function of the doubly truncated exponential distribution is defined by:

$$
\mathrm{P}(\mathrm{T}=\mathrm{t} / \lambda)=\frac{\lambda \cdot \exp (-\lambda \cdot \mathrm{t})}{\phi(\lambda)}
$$

For $\lambda$ greater than zero and $t$ lying between the constants $\mathrm{CI}_{1}$ and $\mathrm{C}_{2}\left(\mathrm{C}_{2}>\mathrm{CI}\right)$ and where the denominator is given by:

$$
\phi(\lambda)=\exp (-\lambda \cdot \mathrm{CI})-\exp \left(-\lambda \cdot \mathrm{C}_{2}\right)
$$


The method of maximum likelihood was employed to estimate $\lambda$ and yielded, in these data (Table I), a value of 0.1521 ( \pm 0.0085$)$ when $C_{I}$ and $\mathrm{C}_{2}$ are one and 54 months, respectively.

Corresponding to equation (I) the hazard or agespecific death rate is given by:

$$
\phi(T=t / \lambda)=\frac{\lambda \exp (-\lambda \cdot t)}{R(t, \lambda)}
$$

where $\mathbf{R}(t, \lambda)=\exp (-\lambda t)-\operatorname{cap}\left(-\lambda \cdot \mathbf{C}_{2}\right)$. Equation (2) is a non-decreasing function of time, rising from approximately $\lambda$ (when $\mathrm{t} \rightarrow \mathrm{Cr}$ ) to infinity (when $t \rightarrow \mathbf{C 2}$ ). 